\title{
Entre o profano e o sagrado: ritos, símbolos e mitos na campanha de um time de futebol brasileiro
}

\author{
Heloisa Juncklaus Preis Moraes, Lucas Pereira Damazio \& Luiza Liene Bressan \\ Universidade do Sul de Santa Catarina, Brasil \\ E-mail: heloisapreis@hotmail.com/lucas_damazio722@hotmail.com/ \\ luizalbceyahoo.com.br
}

\begin{abstract}
Resumo
Este estudo objetiva compreender o sagrado a partir do espaço de um campo de futebol, os símbolos evocados pelo nome do estádio e, principalmente, a aura de glória expressa pelo nome de um atleta que fez parte de um momento histórico na existência do clube brasileiro Palmeiras que defendeu no ano de 2015. Para empreender a pesquisa, elaboramos um escopo teórico baseados nos postulados de Eliade, estudioso do sagrado e de suas manifestações. Também, pelo viés dos conceitos da psicologia junguiana, do imaginário de Durand e Maffesoli,

zada. Como metodologia, utilizamos a mitocrítica, método de análise proposto por Durand ao conceber a teoria antropológica dos estudos da imagem. Esta metodologia nos permite analisar, a partir dos símbolos, a narrativa mítica que se enreda nos objetos culturais, neste caso, a questão do sagrado associada símbolos conquistas de um time de futebol. Os estudos apontaram a imbricação entre sagrado, simbologia e mitos que se presentificam na relação entre uma torcida apaixonada, o nascimento de um herói e de seu espaço sagrado.
\end{abstract} tecemos argumentos que fortalecem a análise reali-

Palavras-chave: espaço sagrado; símbolos; herói; mito; futebol.

\section{Between the profane and the sacred: rites, symbols and myths in the campaign of a Brazilian football team}

\begin{abstract}
This study aims to understand the sacred from the space of a football field, the symbols evoked by the name of the stadium and, mainly, the aura of glory expressed by the name of an athlete who was part of a historical moment in the existence of the brazilian club Palmeiras that defended in the year 2015.

To undertake the research, we elaborate a theoretical scope based on the postulates of Eliade, a scholar of the sacred and its manifestations. Also, due to the bias of the concepts of Jungian psychology, the imaginary of Durand and Maffesoli we weave arguments that strengthen the analysis performed.
\end{abstract}

Data de submissão: 2018-01-12. Data de aprovação: 2018-04-26.

A Revista Estudos em Comunicação é financiada por Fundos FEDER através do Programa Operacional Factores de Competitividade - COMPETE e por Fundos Nacionais através da FCT - Fundação para a Ciência e a Tecnologia no âmbito do projeto Comunicação, Filosofia e Humanidades (LabCom.IFP) UID/CCI/00661/2013.
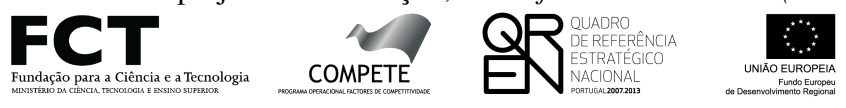

】跑兽

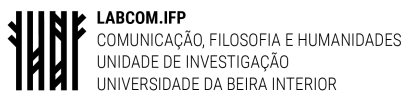


As a methodology, we use the mitochristic method of analysis proposed by Durand when conceiving the anthropological theory of image studies. This methodology allows us to analyze from the symbols the mythical narrative that is entangled in cultural objects, in this case, the question of the sacred asso- ciated with the achievements of a football team. The studies pointed to the imbrication between sacred, symbology and myths that are present in the relationship between a passionate crowd, the birth of a hero and his sacred space.

Keywords: sacred space; symbols; hero; mith; football.

\section{INTRODUÇÃO}

E MBORA o mundo moderno tenha passado por inúmeras mudanças culturais, tecnológicas, sociológicas e econômicas nos últimos séculos, a religiosidade, ainda que se considere o número de ateus, possui forte influência no pensamento tanto ocidental como oriental. Talvez não tanto como uma influência dogmática, como no período medieval, época na qual as religiões ditavam as regras do jogo, mas como um instrumento de alívio diário, ou melhor, enquanto forma de fuga da realidade, que permite a contemplação em algo metafísico, que está para além da materialidade do mundo humano, do sensível e do racional, pois, pela sua força simbólica, auxilia na luta contra os monstros terrenos (enfermidades), assim como no duelo contra o mais poderoso de todos os dragões: a própria morte. Assim como já, pelo viés do sagrado, analisamos narrativas literárias e questões de identidade (Moraes e Bressan, 2016).

Essa crença religiosa ainda permanece possivelmente pelo fato do homem moderno, em sua jornada interior, continuar necessitando do divino e caminhando em direção ao sublime, ao que Eliade (2010) chama de sagrado. Ao explicitar o fenômeno do sagrado, Eliade (2010) atribuilhe uma dimensão espacial, pois o sagrado se manifesta, em sua essência, em um lugar, que se torna sagrado e se diferencia do espaço comum, classificado por ele como profano. Esta dimensão espacial constitui um dos aspectos mais significativos da distinção entre o sagrado e o profano.

O ser humano, durante as batalhas da vida, descobre, muitas vezes, que sozinho não tem forças para enfrentar alguns inimigos que vagam pela terra e pela sua própria imaginação. Por isso evoca, por meio dos mais variados ritos (orações, danças folclóricas, sacramentos, atos violentos, batismos), o sagrado. Em outras palavras, o homo religiosus acredita que exista o que Eliade (2010, p. 17) chama de "a manifestação da ordem do diferente - de uma realidade que não permanece ao nosso mundo". Com isso, encontra o conforto e o apoio para enfrentar os temores que têm durante sua vida terrena.

Para o autor, o sagrado existe em oposição ao profano. Ele é concebido, conforme Eliade (2010, p. 17), "como uma realidade diferente das realidades naturais", pois não é um mundo comum, o mundo humano, mas transcendente, ligado aos deuses e às divindades, que ultrapassa os limites do real, do sensível e, muitas vezes, da própria compreensão dos seres humanos. Esse sagrado, segundo aponta Eliade (2010, p. 17), "é revelado através de sinais, de gestos, de elementos, de objetos, os quais são definidos pelo autor como hierofanias, ou seja, manifestações do sobrenatural, do suprareal". 
Pode-se afirmar que as hierofanias nascem a partir do momento em que "algo sagrado se revela", tanto em uma pedra ou em uma árvore, quanto em um objeto qualquer. Nesse instante, conforme afirma Eliade (2010, p. 17), "a pedra sagrada, a árvore sagrada não são adoradas como pedra ou como árvore, mas justamente porque são hierofanias, porque revelam algo que já não é nem pedra, nem árvore, mas o sagrado, o "ganz andere." Com essas palavras, o autor indica que, dentro das crenças humanas, há uma força além do entendimento do homo sapiens, uma possibilidade que insiste em fazer o ser humano entrar em contradição à razão, ao lógico, ao tangível.

No entanto, o autor, ao tratar do sagrado, não se limita a dizer que as suas manifestações se apresentam apenas sob os aspectos de crenças católicas, budistas, judias, muçulmanas, indígenas e outras que são universalmente conhecidas. Pelo contrário, na visão de Eliade (2010), o sagrado pode se relevar em qualquer lugar, em qualquer objeto, em qualquer elemento que, para um determinado indivíduo, tenha uma relação com o sobrenatural.

Diante dos estudos propostos pelo autor, que evidencia a influência do sagrado na vida do ser humano e da sua importância enquanto fonte de sentido e de resistência ao profano, surge uma questão problemática: poderia, então, um time de futebol ser uma potencializador de hierofanias? E mais: quais hierofanias são criadas por ele? Para tentar responder esta pergunta, foi delimitado como objetivo de pesquisa analisar a trajetória da Sociedade Esportiva Palmeiras, bem como seus símbolos, seus ritos e seus mitos no ano de 2015, período em que o time foi destaque nacional e se tornou Campeão da Copa do Brasil, subsidiado pelos estudos do já mencionado Mircea Eliade (2010), assim como de teóricos da área do Imaginário, da mitologia e da psicologia profunda.

O estudo, portanto, tem como meta evidenciar as simbologias que permearam ritos que marcaram o ano de 2015, inclusive um dos heróis das conquista cujo nome Gabriel Jesus evoca o sagrado na tradição católico-cristã. É na dialética do sagrado e do profano que procuraremos realizar as reflexões aqui pretendidas.

\section{O SAGRADO E SUAS MANIFESTAÇÕES}

No decurso da vida profana, aquela que se distancia da presença dos deuses e das divindades, o homo sapiens, ciente da sua finitude e das calamidades que se apresentam dia após dia aos seus olhos, necessita fugir do sentimento de pavor que o inquieta e o persegue, por isso busca sagrado: outra realidade, o sobrenatural. Conforme Eliade (2010), o sagrado significa, para aquele cuja fé é real, acima de tudo, poder. Na compreensão do autor, esse poder se manifesta das mais variadas e possíveis maneiras, dentre elas: pelos espaços, pelos ritos, pelos símbolos, e, principalmente, pelos mitos.

Nos espaços, Eliade (2010) indica que o sagrado permite ao indivíduo de fé obter "um ponto fixo, possibilitando, portanto, a orientação na homogeneidade caótica, a "fundação do mundo", o viver real". Nesses recintos, deve haver, como cita o autor (2010), uma abertura para o alto, por onde os deuses e as criaturas divinas podem descer à Terra e o ser humano pode subir simbolicamente ao Céu. É desse modo que muitos templos, mesquitas, igrejas, sinagogas e outras estruturas religiosas são planejadas e construídas, com uma "porta" sempre aberta em direção ao Céu e pronta para receber a comunicação dos deuses. Os espaços sagrados são localidades que 
se tornam o centro do universo para homo religiosus, pois além de proteger e de abrigar, também servem como um símbolo de origem, uma vez que, segundo Eliade (2010), é possível entrar em contato com os superiores por meio desses lugares e retornar ao tempo primordial, isto é, ao tempo de fundação da humanidade.

Nos ritos, o sagrado se manifesta pela reatualização de um acontecimento divino, realizado em tempos e em espaços distantes, por personagens que normalmente são representados em formas de figuras sublimes. Nas palavras de Eliade (2010, p. 93), os ritos são festas religiosas, cujos participantes, após realizarem atos de idolatria e de sacríficos, tornam-se "contemporâneos dos deuses e dos Seres semidivinos. Vivem no Tempo primordial santificado pela presença e atividades dos deuses". Com esses dizeres, o autor indica que o ser humano, no instante que venera seu deus ou seus deuses, aproxima-se deles e volta ao Tempo de Origem, ao tempo quando a humanidade começou, quando as divindades criaram o universo e tornaram a vida humana possível. Essas festividades, portanto, são atividades que possibilitam o encontro com o sobrenatural. Quanto mais são repetidas, aprimoradas, autenticadas, o homem religioso encontra a possibilidade de transfigurar sua própria existência e, enfim, tornar-se um ser semelhante ao modelo divino.

Nos símbolos, o homem religioso encontra um modo de expressar a relação imaginária que tem com os seus deuses. Na concepção de Ferreira-Santos e Almeida (2012), são as recorrências simbólicas, ou seja, a repetição de determinadas imagens que permitem compreender, bem como representar uma suposta realidade. Os símbolos, como sugerem os autores (2012), são redes figurativas que possibilitam o surgimento do que está ausente, do indizível, do indescritível. Para Eliade (2013), os símbolos são formas de hierofanias, uma vez que são instrumentos para algo sagrado se revelar, algo que não aparece, mas precisa se libertar. Os símbolos ou objetos sagrados, como profere o autor (2013), são instrumentos que manifestam uma realidade inteiramente diferente das outras, um Cosmos sagrado, pois tem o poder de aproximar o homem religioso das suas divindades.

Nos mitos, o homo religiosus encontra modelos/exemplos para fugir da profanação e seguir em direção ao sagrado. Eles contam uma história santificada, a narração daquilo que os deuses e os seres divinos fizeram no começo do tempo. Essas narrativas, por serem repletas de heroísmos e de lições de moral, tornam-se o modelo exemplar de todas as atividades humanas, pelo fato de que revelam o divino, o superabundante, o eficaz. É essa definição que parece ter Eliade (2010, p. 86) sobre o mito:

"Dizer" um mito é proclamar o que se passou ab origine. Uma vez "dito", quer dizer, revelado, o mito torna-se verdade apodítica: funda a verdade absoluta. "É assim porque foi dito que é assim", declaram os esquimós netsilik a fim de justificar a validade de sua história sagrada e suas tradições religiosas. O mito proclama a aparição de uma nova "situação" cósmica ou de um acontecimento primordial. Portanto, é sempre a narração de uma "criação": conta se como qualquer coisa foi efetuada, começou a ser É por isso que o mito é solidário da ontologia: só fala das realidades, do que aconteceu realmente, do que se manifestou plenamente.

O mito, como sugere o autor (2010), tem sempre um sentido de representação coletiva, transmitida por meio de várias gerações e que procura, inesgotavelmente, uma explicação para o mundo, para o homem e, claro, para sua existência. O mito é, por consequência, a revelação 
pela narrativa, pela palavra, uma manifestação pelo dizer, pelo verbo e pelo substantivo, ou seja, um relato das simbologias, das imagens, das construções imaginárias do ser humano e, acima de tudo, da sua imaginação. Dito de outro modo, o mito, conforme observa Brandão (1986), é a linguagem imagística dos princípios. Ele traduz a origem dos homens, dos hábitos, dos gestos, da economia, da religião, da política e de toda a vida social. Mito é, pois, segundo menciona autor, a narrativa de uma criação que pretende explicar o homem e o mundo: ele conta como algo, que não era para a humanidade e para o universo, começou a ser e, consequentemente, a produzir sentidos, imagens, símbolos, crenças e outras formas de manifestações psíquicas. Segundo Brandão (1986):

O mito expressa o mundo e a realidade humana, mas cuja essência é efetivamente uma representação coletiva, que chegou até nós através de várias gerações. E, na medida em que pretende explicar o mundo e o homem, isto é, a complexidade do real, o mito não pode ser lógico: ao revés, é ilógico e irracional. Abre-se como uma janela a todos os ventos; presta-se a todas as interpretações. Decifrar o mito é, pois, decifrar-se. (Brandão, 1986, p. 36).

No entanto, Brandão (1986) alerta que o mito não pode ser entendido como o sinônimo de fábula, de fantasia, de bruxaria, de farsa, de ficção, de lenda ou de uma invenção qualquer da humanidade, pois, para o autor, existem muitas verdades nessa forma do homem justificar sua existência e estabelecer relações com o seu próprio eu. Segundo Brandão (1986), o conceito de mito apresenta-se como uma verdade que esconde outra verdade. Em outro modo de dizer, o mito seria uma verdade profunda e viva na psique humana, um sentindo profundo que faz a humanidade tentar compreender a sua própria vivência neste universo. Para Brandão (1986):

É necessário deixar bem claro, nesta tentativa de conceituar o mito. que o mesmo não tem aqui a conotação usual de fábula, lenda, invenção, ficção, mas a acepção que lhe atribuíam e ainda atribuem as sociedades arcaicas, as impropriamente denominadas culturas primitivas, onde mito é o relato de um acontecimento ocorrido no tempo primordial, mediante a intervenção de entes sobrenaturais. Em outros termos, mito, consoante Mircea Eliade, é o relato de uma história verdadeira, ocorrida nos tempos do princípio, illo tempôre, quando, com a interferência de entes sobrenaturais, uma realidade passou a existir, seja uma realidade total, o cosmo, ou tão-somente um fragmento, um monte, uma pedra, uma ilha, uma espécie animal ou vegetal, um comportamento humano (Brandão, 1986, p. 36).

Danielle Perin Rocha Pitta (2005), pesquisadora dos estudos sobre o imaginário, principalmente dos conceitos propostos por Gaston Bachelard, Gilbert Durand e Michel Maffesoli, também compreende que o mito é um sistema dinâmico de símbolos que compõe um relato, isto é, uma narrativa apresentada em forma de história, um relato fundante da cultura que estabelece relações entre o homem e o universo. Todavia, a autora amplia ainda mais esse conceito sobre o mito. De acordo com Pitta (2005), a partir dos estudos de Mircea Eliade (1907-1987), o mito trata-se, sobretudo, da experiência existencial humana, que permite o homem a compreender-se e encontrar-se. O mito é, portanto, a atividade criadora do espírito humano que busca justificar a existência, a própria vida. Além disso, Pitta (2005, p. 18) ainda complementa que o mito fornece modelos de comportamento, isto é, permite "a construção individual e coletiva da identidade" do ser humano. O mito, desse modo, atua em nossa constituição humana, em nossa trajetória antropológica, como uma bússola que orienta o nosso comportamento, os nossos desejos e a nossa identidade. 
Brandão (1987), ao refletir sobre as questões mitológicas, aponta que é a partir da religião que muitos mitos foram constituídos e reatualizados. É na religião que muitos mitos são manifestados pelo homem e pelo seu desejo de imaginar respostas para a vida. Na visão do autor, pode-se dizer que a religião é, acima de tudo, a reatualização e a ritualização do mito. Com essa afirmação, encera-se, então, esta seção. Na próxima, inicia-se, portanto, a análise do estudo, feito com base nos autores citados.

\section{OS Ritos PARA CELEbRAR O NASCIMENTO DE UM NOVO MESSIAS}

$\mathrm{O}$ ano de dois mil e quinze começou repleto de expectativas para o Palmeiras. De acordo com o Globo Esporte ${ }^{1}$ (2015), portal de notícias especializado em futebol, aquele ano tinha tudo para ser promissor:

Reconstrução. Assim pode ser definido o ano de 2015 do Palmeiras. Depois de disputar a Série B em 2013 e lutar contra o rebaixamento até a última rodada do Campeonato Brasileiro de 2014, o Verdão promoveu uma grande reformulação no departamento de futebol profissional.

Após acertar um acordo milionário com José Roberto Lamacchia, proprietário da empresa Crefisa e da Faculdade das Américas (FAM), o time iniciou um longo processo de negociação para a contratação de quarenta novos atletas, cujo objetivo era montar uma equipe consistente defensivamente e agressiva ofensivamente. Conforme o Globo Esporte (2015), "No total, foram 25 jogadores contratados, mais de 20 atletas negociados, nova diretoria e duas comissões técnicas". No entanto, mesmo com todo o dinheiro investido e coordenado por uma nova gestão administrativa, que parecia fazer o máximo para o time prosperar, os resultados não surpreendiam e a equipe oscilava entre excelentes e péssimos jogos.

Entre tropeços e acertos, o time, embora ainda muito inseguro, desequilibrado e sem um padrão de jogo aparentemente definido, chegou à final do Campeonato Paulista. Contudo, após dois jogos tensos, o título do campeonato ficou com o Santos, um dos rivais históricos do Palmeiras. Depois do tropeço, que gerou uma imensa irritação nos torcedores e certa insegurança da diretoria em relação ao treinador, o time iniciou uma nova caminhada a fim de conquistar outra competição: a Copa do Brasil.

Nessa competição, desde os primeiros jogos, o Palmeiras parecia um time diferente: mais seguro, confiante, explosivo. Possivelmente, um dos fatores para essa mudança foi a entrada de um jovem jogador no time titular, chamado de Gabriel Jesus. Menino Jesus, como a torcida gritava nas arquibancadas, tornou-se o novo ídolo do time. O atleta, morador de um bairro humilde de São Paulo e possuidor de uma história de dificuldades, começou a se tornar um dos protagonistas da equipe. Jogo após jogo, o jovem atleta se destacava e conseguia fazer gols e assistência importantes para o Palmeiras avançar na competição.

No decurso da Copa do Brasil, os torcedores então notaram que algo especial se revelava aos seus olhos. Algo que não acontecia há mais de 20 anos para o Palmeiras: nascia um novo messias, um jovem rapaz capaz de libertá-los de dois séculos de angústias e de sofrimentos. Gabriel Jesus,

1. Disponível em: http://globoesporte.globo.com/futebol/times/palmeiras/noticia/2015/12/chapeu-revelacoes-eadeus-do-mago-o-ano-de-2015-do-elenco-palmeirense.html. Acesso em: 12/dez/2017. 
tanto pelo seu nome quanto pela sua história humilde, tinha a sua imagem ligada ao filho do Deus do Cristianismo: o Jesus Cristo. Nos jogos, inclusive, a torcida, quando o observava o atleta tocar na bola, cantava "Glória, glória, aleluia, é Gabriel Jesus!". Esse cântico ${ }^{2}$, repetido partida após partida durante a Copa do Brasil, releva que os torcedores do Palmeiras viam em Gabriel Jesus a figura de alguém/algo sagrado. Nascia um herói que, de acordo com Jung (2016, p. 142), "tem um flagrante poder de sedução dramática e, apesar de menos importante, uma importância psicológica profunda". E com a evocação do nome de Gabriel, anjo guardião, aquele que teve a grandiosa missão de anunciar a vinda do Messias, acompanhado do nome de Jesus criou o ritual que fez surgir o herói "de nascimento humilde mas milagroso, provas de sua força sobre-humana precoce, sua ascensão rápida ao poder e à notoriedade, sua luta triunfante contra as forças do mal, sua falibilidade ante a tentação do orgulho (hibris) e seu declínio, por motivo de traição ou por um ato "heroico", no qual sempre morre (Jung, 2016, p. 142).

Assim, que entrava em campo, ecoava o "glória, glória Aleluia" que em sua significação também evoca o sagrado, pois em hebraico a palavra aleluia pode ser definida como 'louvem a Deus'. Havia por parte da torcida um processo de endeusamento do atleta.

Essa canção, interpretada por um grande número de torcedores, que enlouquecido entoava em coro uma melodia apaixonada e com referências aos hinos católicos, apresenta indícios de ser uma ritualização e uma crença de que Gabriel Jesus era uma representação de uma espécie de um novo salvador. Conforme Eliade (2010), os ritos são instrumentos para a humanidade se aproximar dos deuses, uma imitação e uma reprodução dos atos e dos gestos divinos. Na leitura do autor sobre o assunto, quando o ser humano realiza um rito, ou seja, repete os modelos divinos; por um lado, mantém-se sagrado e protegido; por outro lado, santifica seu mundo e contribui para uma "divinização" do seu espaço.

Nesse caso, o rito, cantado pela torcida do Palmeiras, que entoava "Glória, glória, aleluia, é Gabriel Jesus!", era um instrumento para evocar um ser que consideram divino nos momentos mais adversos da partida, assim como criar uma atmosfera sagrada dentro do estádio. Como o atleta tem uma semelhança com o nome de Jesus Cristo, observa-se que esse rito era uma forma encontrada pelos torcedores, segundo uma interpretação eliadiana, para manter seu "messias" divino, protegido e simbolicamente "vivo", assim como santificar seu universo, seu "Olimpo", ou seja, o próprio estádio da equipe.

Esse rito, pela entonação, pela letra e até pela melodia apresentada, sugere uma referência, como já foi mencionada acima, aos cânticos e aos rituais cristãos cultuados nos eventos paroquiais. Por apresentar essas características, o rito realizado durante as partidas, conforme aponta Eliade (2010, p. 98), "têm uma finalidade trans-histórica - a salvação". Nessa perspectiva, o rito em celebração ao Gabriel Jesus, portanto, é utilizado como uma forma de salvar o time de anos longe das glórias e das conquistas,

Gabriel Jesus assume nesse rito, de forma metafórica, o arquétipo do Salvador ou, de acordo com Pearson (1991), do Caridoso. Na análise da autora, o Caridoso é considerado o arquétipo da generosidade. Quando está ativo nos níveis mais elevados da psique humana, o resultado é uma energia caridosa, com qualidades transformadoras de doação e, muitas vezes, de sacrifício. São

2. Disponível em: www.youtube.com/watch?v=-3zysLYnYOk. Acesso em: 12/dez/2017. 
exemplos de Mártires Modelares, nas palavras Pearson (1991), figuras como: "Cristo, Gandhi, Martin Luther King, Florence Nightingale, Madre Teresa de Calcutá e toda a pessoa que tenha dedicado sua vida aos outros".

Pearson (1991) descreve o Caridoso como o arquétipo que cria um sentido de comunidade, encorajando relacionamentos profundos entre pessoas e instituições. Eles produzem, por meio do afeto que carregam dentro da psique, uma atmosfera no qual todos se sentem mais seguros e protegidos. No caso do Gabriel Jesus, por ter sido evocado como o novo salvador do Palmeiras, ele parecia incorporar dentro de campo esse arquétipo. Ele é, pela sua personalidade humildade, dedicada e inocente, uma representação simbólica do Caridoso. Durante os jogos da Copa do Brasil, Gabriel lutou partida após partida, mas nunca de forma desleal ou agressiva com os adversários, sempre com um jeito pacífico, típico de alguém que incorporou o papel de messias do time.

\section{O NÚMERO TRINTA E TRÊS E SEU VALOR SIMBÓLICO}

Nas palavras de Jacobi (1990), pesquisador da psicologia junguiana, o conceito de símbolo pode ser designado como uma manifestação consciente dos arquétipos. Pode-se afirmar, dessa forma, que cada símbolo é uma espécie de esboço real de uma imagem coletiva e abstrata. O autor, para exemplificar, cita que o inconsciente fornece, por assim dizer, uma espécie de forma, que é preenchida, incessantemente, por um material consciente, chamado de símbolo.

Jacobi (1990, p. 72), para elucidar essa questão sobre o símbolo, realizou a seguinte reflexão: "o "arquétipo em si", ele é, sem dúvida alguma, sempre um símbolo potencial e, quando existe uma constelação psíquica geral ou uma posição adequada do consciente, ele está sempre pronto para se atualizar e aparecer como símbolo". Com essa colocação, o autor indica que os arquétipos são as fontes, enquanto os símbolos são suas formas de manifestações.

No caso do Palmeiras, a diretoria e os profissionais de marketing, ao notarem que Gabriel Jesus evocava uma energia divina, isto é, figurava, no imaginário dos torcedores, o próprio arquétipo do salvador, imediatamente buscaram formas de simbolizá-lo como uma espécie de messias. Com isso, Gabriel ganhou, durante a Copa do Brasil, a camisa número trinta e três. Esse número ${ }^{3}$, segundo conhecem os cristãos, era a idade que Jesus Cristo foi crucificado, morto e ressuscitado.

3. Disponível em: http://globoesporte.globo.com/futebol/times/palmeiras/noticia/2016/07/artilheiro-e-xodo-gabri el-jesus-tem-camisa-mais-vendida-no-palmeiras.html. Acesso em: 12/dez/2017. 


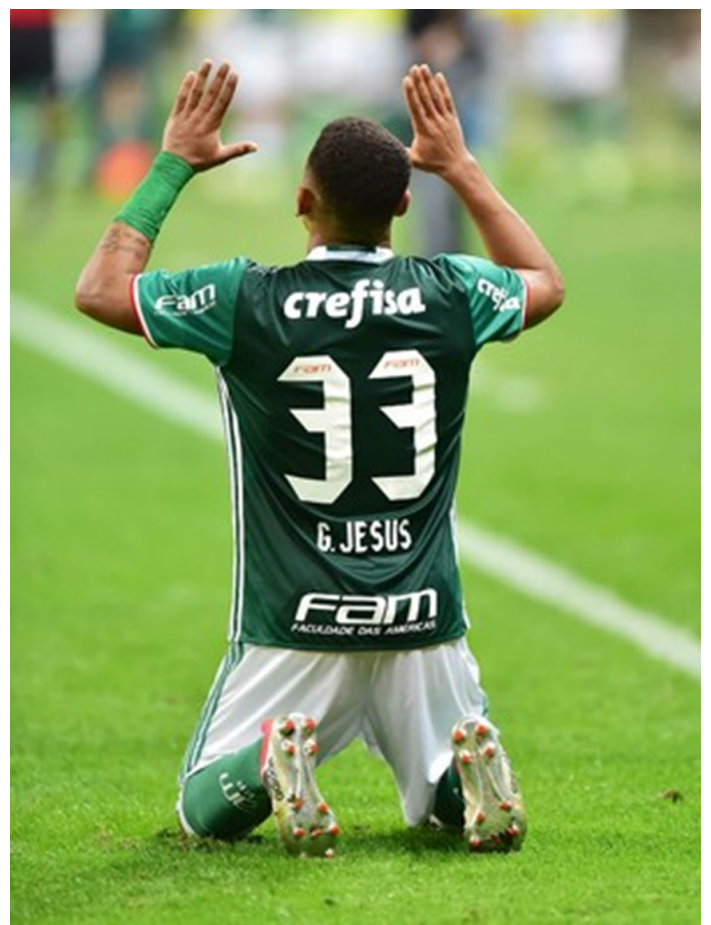

Imagem 1. Gabriel Jesus, o número 33

Fonte: Globo EsPorte, 2016.

Conforme mencionado por Jacobi (1990), os símbolos designam, por trás de um objeto visível, palpável e real, algo inconsciente, profundo e invisível, definido como arquétipo. No exemplo do número trinta e três, analisa-se, por esse ponto de vista, que a camiseta, um objeto, que é uma representação real, um elemento sensível, tornou-se, pela energia religiosa que transmitia aos torcedores do Palmeiras e aos fãs do jogador, um símbolo que retratava algo profundo da psique humana: a imagem abstrata de um herói salvador, ou como mencionado anteriormente, de acordo com a definição de Peason (1991), o arquétipo do caridoso.

Na perspectiva de Eliade (2010), os símbolos são formas que manifestam uma realidade inteiramente diferente das outras, um Cosmos sagrado. Ao analisar o número trinte e três da camiseta do jogador Gabriel Jesus, é possível verificar que este objeto, um simples utensílio de uso diário, transformou-se em uma hierofonia, um "elemento sagrado", usado por um novo messias, que chegou para acabar com os anos de sofrimento da Sociedade Esportiva Palmeiras.

Desse modo, a camiseta, lançada pela equipe de marketing em dois mil e quinze, tornou-se um símbolo de proteção para o jogador, "algo que traz sorte", conforme foi citado pelo próprio Gabriel Jesus em uma reportagem realizada pelo Jornal Extra ${ }^{4}$. Gabriel, mesmo após ser transferido para Europa, quando decidiu jogar no Manchester City, time da primeira divisão inglesa, optou por

4. Disponível em: https://extra.globo.com/esporte/gabriel-jesus-escolhe-camisa-33-no-city-mesma-que-vestia-nopalmeiras-20796902.html. Acesso em: Acesso em: 12/dez/2017. 
permanecer com este número, ou melhor dizer, com este símbolo, pois, para o jogador, ele é algo que deseja carregar para a vida toda, "uma potência sagrada".

\section{O eSPaÇO SAgRado dos Palmeirenses: BeM-Vindo aO Allianz Park}

Em dois mil e quinze, os palmeirenses viram nascer o seu novo lar: o Allianz Park.

O estádio tinha muitas qualidades que os torcedores desejavam, como: cadeiras especiais, um gramado estilo europeu, lanchonetes, estacionamento, áreas de lazer, entre outros confortos. Ele é descrito, site oficial do estádio ${ }^{5}$, como "a arena multiuso mais moderna do país concebida para receber esportes, entretenimento e eventos corporativos".

A escolha do nome Allianz, do alemão aliança, é uma evocação ao sagrado. Aliança é também o elo bíblico estabelecido entre o povo de conduzido por Moisés e Deus. Entretanto, esse estádio, embora com uma infraestrutura de alto padrão, não apresentava o que os palmeirenses mais valorizavam enquanto torcedores: os títulos.

O Palmeiras, o maior campeão nacional, estava de casa nova, mas não tinha inaugurado ainda sua sala de troféus. Faltava um título, um elemento simbólico que fosse capaz de "sacralizar" o estádio. Com essa situação inconfortável, os torcedores se viam, segunda uma interpretação do ponto de vista de Eliade (2010), sem um ponto fixo e não se localizam no que o autor chamava de "Centro do Mundo". Logo, eles viviam em profanação, longe do divino, do próprio sagrado. Afinal, o elemento sagrado, a hierofania que traria o equilíbrio espiritual entre os torcedores, ainda não tinha sido colocada no estádio.

O Allianz Park tinha muitas características para ser um espaço sagrado. Ele continha o que Eliade (2010) considera essencial em uma estrutura divina, uma abertura para o alto, por onde os deuses e as criaturas divinas descem à Terra e o ser humano pode subir simbolicamente ao Céu. $\mathrm{O}$ estádio ${ }^{6}$ tinha essa "porta" sempre aberta em direção ao Céu e pronta para receber a comunicação "dos deuses".

5. Disponível em: www.allianzparque.com.br/sobre . Acesso em: 12/dez/2017.

6. Disponível em: http://adnews.com.br/negocios/allianz-parque-e-quinta-maior-arena-do-mundo-em-numero-deseguidores.html. Acesso em 12/dez/2017. 


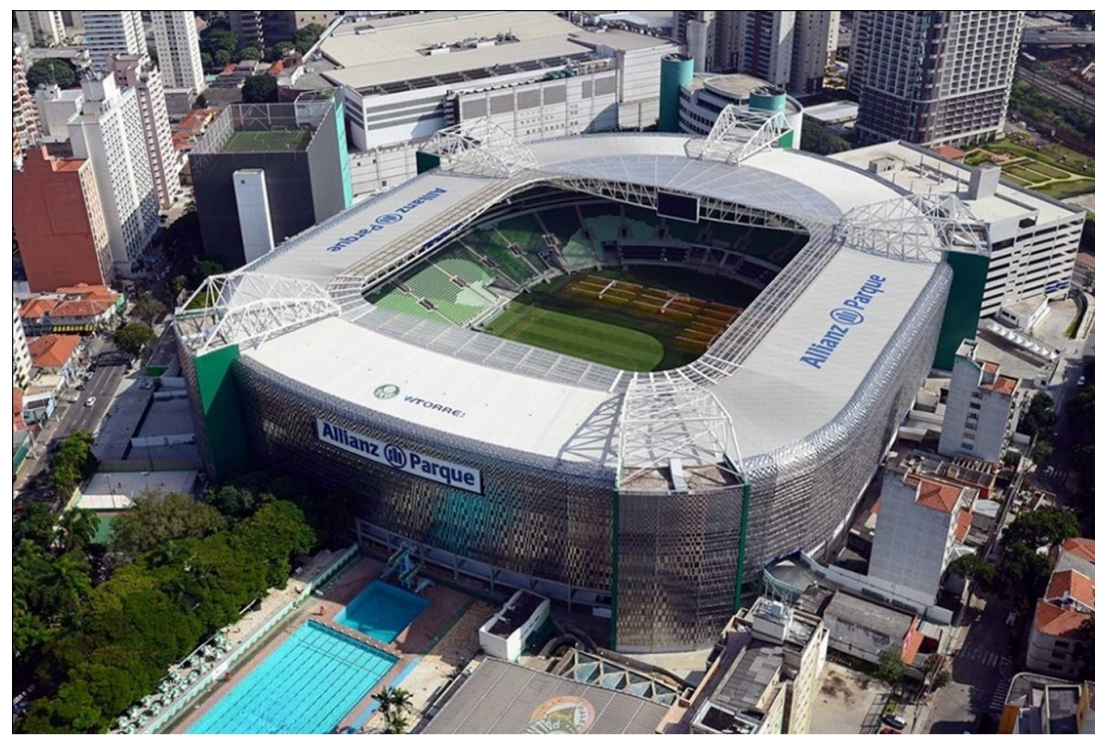

Imagem 2. O espaço do sagrado palmeirense Fonte: Allianz PARK, 2017.

No entanto, a presença do sagrado não se fazia presente. Essa presença, que tanto almejavam os palmeirenses, ainda tinha que ser conquistada por meio de um ato heroico, efetuada por um messias, um herói capaz de triunfar entre os adversários e trazer, como cita Campbell (1997), ao tratar da jornada do herói, o elixir para casa (nesse caso, o título da Copa do Brasil). É neste momento que surge a figura de Gabriel Jesus. O jovem, por ser visto como uma figura heroica pelos palmeirenses, produziu no imaginário dos torcedores, pela sua história de vida humilde e pela semelhança com o nome de Jesus Cristo, uma imagem mítica.

\section{A CONSAgraÇão de Gabriel Jesus: o FOrTalecimento do Mito}

Brandão (1985, p. 36), ao descrever o mito, afirma que se trata de uma narrativa da criação, ele "conta-nos de que modo algo, que não era, começou a ser". Para o autor, o mito é um enredo que fixa um acontecimento no coração do ser humano. Ele expressa o mundo, a essência e a própria realidade humana.

Para o senso comum, o mito quase sempre é tido como expressão de fantasia, de loucura, de mentiras ou até mesmo de ilusão, mas não é assim que Brandão (1985) compreende essa expressão. Segundo o pesquisador, o mito é a palavra relevada, o dito, é a expressão das angustias, das alegrias e das conquistas dos seres humanos. O mito é, em outras palavras, a narrativa da profundeza da humanidade.

Na descrição de Eliade (2010), ao estudar os estoicos e suas representações religiosas em épocas arcaicas, um ser, para ter sua história narrada e se tornar uma figura mitológico, era necessário prestar, por meio de uma variedade de missões e de rituais, serviços à humanidade. 
Contudo, Maffesoli (1996), em sua análise a respeito da pós-modernidade, feita na obra No fundo das Aparências, indica que o ser humano vive outro momento, centrado na aparência, na futilidade, nas mercadorias e nas banalidades das coisas cotidianas. Nesse contexto, o corpo, a moda, a publicidade, o cinema e as atuais manifestações urbanas criam a consciência e instituem o movimento social. Pela perspectiva do referido autor, o mito, nesse caso, não precisa ser necessariamente a narrativa de um ser divino, uma alma sobrenatural, com poderes mágicos, que se dedica à humanidade, pois, para o homem pós-moderno, o que importa é o aqui e o agora, o imediato, o fazer no presente.

Com esse olhar, consegue-se verificar o porquê da trajetória de Gabriel se tornar uma narrativa mitológica para os palmeirenses. Pelo fato do "banal", do "fútil", como um time de futebol, ganhar uma efervescência no imaginário coletivo na era pós-moderna e se tornar uma potencializadora de mitos. Mitos que nos interpelam através de imagem:

\begin{abstract}
A imagem é estruturante neste contexto. Não nos referimos somente à imagem estática, mas a imagem-mundo. Se partirmos do pressuposto que a mídia e seus dispositivos tecnológicos são a mais importante produtora de efeitos de sentido sobre a realidade ou, ao menos, seleciona os fatos a serem discutidos socialmente, também é importante destacar que muito desta seleção nos chega através de imagens. Não só imagens materiais, mas imagens-conceito, imagens enquanto valor. Criação imaginal para a partilha do sensível, marca da socialidade contemporânea. Mescla paradoxal entre o impalpável e o real que faz sentido, como veremos adiante no relato das experiências (Moraes, 2017, p. 187).
\end{abstract}

Nesse período histórico, que Maffesoli (1996) conceitua de pós-modernidade, não só o Gabriel Jesus pode se tornar um mito, mas muitos outros. Se for realizar uma análise prévia dos últimos 50 anos, o Brasil colecionou mitos, figuras como Pelé, Garrincha, Zico, Romário, Ronaldo, entre tantos jogadores foram e ainda são idolatrados. O que constata, como insinua Maffesoli (1996), que coisas aparamente insignificantes, podem fortalecer as relações entre os indivíduos e ganhar um status especial, uma condição de divinização. Desse modo, um simples menino, morador do Bairro Peri, localizado em São Paulo, pode se transformar em um novo messias, um novo herói mítico. Moraes (2016, p. 147) destaca que, tal como no caso analisado, "o núcleo das histórias, cenários, personagens das manifestações culturais e midiáticas contemporâneas estão cobertas de valores e conceitos das divindades alegóricas que compõem o mito, expressando schèmes, arquétipos e símbolos".

Pela própria estruturação teórica do imaginário, deve-se considerar que esses mitos contemporâneos não nascem de um dia para o outro. Eles são potencializados pelos clubes, pelos patrocinadores e pela mídia. No caso do Gabriel Jesus, toda essa imagem mítica em seu entorno não surgiu imediatamente. O Palmeiras certamente teve uma função preponderante. O time utilizou o atleta em diversas campanhas publicitárias que engrandeceram sua imagem perante os palmeirenses. Para além da sedução e significativa tecnologia de instalação de imaginários, percebemos tecnologias do imaginário (Silva, 2003) também como potencializadoras de laço social e um dos principais mecanismos de produção simbólica da atualidade (Moraes, 2016). 


\section{CONSIDERAÇões FinAis}

Neste estudo, delimitou-se como objetivo de pesquisa responder a seguinte problemática, "poderia, então, um time de futebol ser uma potencializador de hierofonias? E mais: quais hierofonias são criadas por ele?" Após uma reflexão e uma análise eliadiana de algumas representações simbólicos apresentados no ano de 2015, pela Sociedade Esportiva Palmeiras, pode-se afirmar que há, de fato, indícios do time produzir no imaginário dos seus torcedores determinadas hierofonias, que também podem ser compreendidas como imagens, conforme nos orienta Wunenburger (2018, p.60):

A imagem é, portanto, intimamente ligada à possibilidade de constituir uma representação do real. Dito de outro modo, de constituir o real tal como ele se dá a nós sob o plano fenomenal. Mesmo preparada e informada por imagens a priori, a imagem perceptiva tem por horizonte a coisa mesma, o que a leva a adaptar ao máximo o estado subjetivo ao estado objetivo, em particular pelo viés da atenção dirigida às coisas.

Segundo foi apresentado durante o estudo, a equipe do Palmeiras, responsável pela imagem do clube, explorou o nome do atleta Gabriel Jesus, associando-o ao sagrado evocado pelo nome de Jesus Cristo, criando símbolos com o intuito de aproximar as duas figuras e produzir no imaginário dos palmeirenses uma imagem sagrada em relação ao seu jogador. Essa análise se averiguou quando, no decurso do estudo, foi apresentado a camiseta número trinta e três. Ao empregar esse número na camiseta do atleta, pode-se perceber que o Palmeiras, além de criar uma excelente ação de marketing, ajudou a potencializar a imagem de messias que o jogador vinha criando no imaginário nos palmeirenses. Fazemos esta afirmativa, pois de acordo com Bachelard e Bergson citados por Wunerburger (2018) há uma continuidade entre devaneio e percepção. E mais:

Passa-se, assim, por níveis seguidamente insensíveis de imagens determinadas por informações primeiras a outras imagens mais determinadas por lembranças, afetos, desejos ou verbalizações poéticas. Perdendo a atenção sobre o conteúdo empírico imediato e objetivo, a consciência substitui o real por uma espécie de irreal, mesmo se este último é constituído de percepções passadas e, portanto, por elementos emprestados da experiência. O onirismo, ainda que mínimo, relaxa a relação com o mundo percebido e dá à imagem uma função ao mesmo tempo de máscara e de espelho do mundo[...] A imagem é, portanto, intimamente ligada à possibilidade de constituir uma representação do real. Dito de outro modo, de constituir o real tal como ele se dá a nós sob o plano fenomenal. Mesmo preparada e informada por imagens a priori, a imagem perceptiva tem por horizonte a coisa mesma, o que a leva a adaptar ao máximo o estado subjetivo ao estado objetivo, em particular pelo viés da atenção dirigida às coisas (Wunerburger, 2018, p.60).

Assim, há um conjunto simbólico que gravitou em torno da imagem do atleta heroicizado, sacralizado pelo Palmeiras que tornaram o ano de 2015 especial aos torcedores e que tornaram o Allianz Park um lugar de manifestação do sagrado.

Além disso, como o homem vive, segundo aponta Maffesolli (1996), em tempos banais, onde o que importa são superficialidades, existe sim a possibilidade de um garoto simples se tonar um herói, um salvador. Nesse pós-modernidade, conforme conceitua Maffesolli (1996), um mundo 
se abre para as coisas supérfluas. Assim, o que se tem valor real são celebridades, as modelos, os jogadores de futebol, ou seja, os novos mitos, os mitos contemporâneos.

\section{REFERÊNCIAS}

Allianz Park (s.d.). Disponível em www.allianzparque.com.br. Acesso em dez. 2017.

Brandão, J. de S. (1986). Mitologia grega, vol. I. Rio de Janeiro: Vozes.

Campbell, J. (1997). O herói de mil faces. 10 ed. São Paulo: Editora Pensamento.

Eliade, M. (2010). O sagrado e o profano: a essência das religiões. 2 ed. São Paulo: Martins Fontes.

Globo Esporte. (s.d.). Disponível em http://globoesporte.globo.com. Acesso em dez. 2017.

Jacobi, J. (1990). Complexo Arquétipo Símbolo na Psicologia de C. G. Jung. São Paulo: Cultrix.

Jung, C. G. (2016). O Homem e seus Símbolos . 3 ed. Especial brasileira (trad. M. L. Pinho). Rio de Janeiro: HarperCollinsBrasil.

Mark, M. \& Pearson, S. C. (2001). O herói e o fora-da-lei: como construir marcas extraordinárias usando o poder dos arquétipos. São Paulo: Cultrix.

Maffesoli, M. (1996). No fundo das aparências. Rio de Janeiro: Vozes.

Moraes, H. J. P. (2016). Sob a perspectiva do imaginário: os mitos como categoria dos estudos da cultura e da mídia. In G. G. B. Flores, N. R. M. Neckel \& S. M. L. Gallo (orgs), Análise do Discurso em Rede: cultura e mídia, v.2. Campinas: Pontes.

Moraes, H. J. P. (2017). Os youtubers e as relações de identificação e projeção no imaginário infanto-juvenil contemporâneo: discussões a partir da ética da estética. Iluminuras, jan/jul, 18(44): 182-196. Porto Alegre.

Moraes, H. J. P. \& Bressan, L. L. (2016). Imaginário e religiosidade na obra "Operários de Primeira Hora" de Valdemar Mazzurana e o regime noturno das imagens. REVELL - Revista de Estudos Literários da UEMS, ago, ano 7, 2(13): 42-58. Ed. Especial.

Pearson, S. C. (1991). O despertar do herói interior: a presença dos doze arquétipos nos processos de autodescoberta e de transformação do mundo. São Paulo. Editora Pensamento.

Pitta, D. P. R. (2005). Iniciação à teoria do imaginário de Gilbert Durand. Rio de Janeiro: Atlântica.

Silva, J. M. da. (2006). As tecnologias do imaginário. Porto Alegre: Sulina.

Wunerburger, J.-J. (2018). A Árvore das Imagens. (trad. A. T. M. P. Barros). Intexto, jan./abr., (41): 58-69. Porto Alegre, UFRGS. Disponível em: http://seer.ufrgs.br/index.php/intexto/artic le/view/77402. 